\title{
A Survey on Chinese Non-English Majors' Intercultural Communication Competence from Four Dimensions
}

\author{
Lili YANG \\ City College, Wuhan University of Science and Technology, Wuhan, 430083, China \\ email: 17150465@qq.com
}

\begin{abstract}
Keywords: Intercultural Communication; Intercultural Communication Competence; Four Dimensions; Non-English Majors
\end{abstract}

\begin{abstract}
IC (Intercultural communication) is by no means a new area to study. It has been so long a history that people interacted with others from different language-cultures. ICC (Intercultural Communication Competence) is also placed as the core competence in the model. At the beginning, the author reviewed a certain amount of literature on intercultural communication. In this thesis, it mainly aimed to investigate on the current situation of intercultural communication competence among today's college English learners in China. It is expected that today's Chinese Non-English majors could in this way examine their intercultural communication competence.
\end{abstract}

\section{Introduction}

Intercultural communication is by no means a new area to study. It has been so long a history that people interacted with others from different language-cultures. There is a consensus that culture and communication are closely associated with each other. Culture is the foundation of communication. [1] Concerning the nonverbal dimension, scholars such as Du Xuezeng (1999), Tang Degen (2000), and Bi Jiwan (1999) have done great and deep researches into the different connotations of nonverbal cues, such as body behavior and concept of time and space in Chinese and Western cultures. [2] In this construct of ICC, there are also five dimensions. These are awareness, attitudes, skills, knowledge (A+ASK), and proficiency in the host tongue. A word of explanation about each will be helpful. [3]For example, one often hears ICC described as host culture "knowledge" while others may stress certain needed "skills." Both knowledge and skills are customarily addressed in traditional educational settings. On the other hand, anyone who has been in a intercultural situation knows that positive attitudes and awareness are just as important, if not more so, to intercultural success. [4]Four Dimensions - ICC has four dimensions; these include: knowledge; (positive) attitudes; skills; and awareness. In the present foreign language teaching, more efforts than necessary are being made to introduce the pure linguistic dimension of language. Traditional foreign language teaching approaches such as vocabulary explanation, grammar analysis and passive translation are still assuming are still dominant. Foreign language teaching is actually the teaching of culture. [5] The importance of culture teaching is due to the fact that it is much easier to be bilingual than bicultural as "it is easier to keep one's linguistic codes separate than one's social codes as one often is not aware of the social codes on a conscious level until they are violated" (Paulston,1990:291). Thus, the research is aimed to investigate on the current situation of intercultural communication competence among today's college English learners in China. It is expected that today's Chinese Non-English majors could in this way examine their intercultural communication competence in this study. 


\section{Methodology}

\section{A. The Research Questions}

What is the current ICC level of Chinese non-English majors from the dimensions of intercultural awareness, attitudes, skills and knowledge?

\section{B. Subjects}

130 Chinese Non-English Majors are the sample testees for this small scale empirical study. The respondents are currently taking their sophomore year from the Science and Engineering to Arts, which gives certain reliability to the sample.

Table 1 Subjects

\begin{tabular}{|cc|c|c|c|c|}
\hline & & & & $\begin{array}{c}\text { Cumulative } \\
\text { Percent }\end{array}$ \\
\hline Valid & Male & 72 & 55.4 & 55.4 & 55.4 \\
& Female & 58 & 44.6 & 44.6 & 100.0 \\
& Total & 130 & 100.0 & 100.0 & \\
\hline
\end{tabular}

\section{Instrument}

The test instrument employed in this pilot study is a questionnaire investigating the four dimensions of ICC, namely, awareness, attitude, skills and knowledge. There are all together 11 items. The questionnaire employed 6-level Likert scale to assess the participants ICC from No Competence (0) to Great Competence (5). Specifically speaking, 0-No Competence, 1-Poor Competence, 2-OK Competence, 3-Good Competence, 4-Great Competence.

\section{Data Collection}

All the students were required to complete the questionnaire after taking the teacher's explanation for reference. Before doing this questionnaire, they were also told that this survey had no relation with their middle or final examination scores for College English Course and thus their choices might reflect their true thinking. 130 valid questionnaires were collected.

\section{Results and Discussion}

The results of analyzed data for the four dimensions of ICC, namely, awareness, attitude, skills and knowledge are displayed in the following table.

Table 2 Four Dimensions

\begin{tabular}{|l|r|r|r|r|r|}
\hline & N & Minimum & Maximum & Mean & Std. Deviation \\
\hline Attitude & 130 & .67 & 4.00 & 2.5385 & .72054 \\
Awareness & 130 & .00 & 4.00 & 2.2513 & .63499 \\
Knowledge & 130 & .00 & 4.00 & 2.1205 & .65625 \\
Skills & 129 & .33 & 3.00 & 1.6848 & .72446 \\
Valid N & 129 & & & & \\
(listwise) & & & & & \\
\hline
\end{tabular}

Table 2 described that these English majors feel competent in the Attitude category. That is to say they have a relative high level of competence in attitude towards Intercultural Communication although it is very significant. It generally tells us students have a good attitude toward communicating in English with the target culture. Among the four dimensions, participants feel least competence in Skills. Such result may root from two facts. One is the lack of training on related subjects and the other is that participants have little chance to develop their skills in real situations. Without adequate training and practice, it is hard for them to be confident in a high level of competence in communication skills. 


\section{A. The Attitude Dimension}

Figure 1 Distribution of Attitude Scores

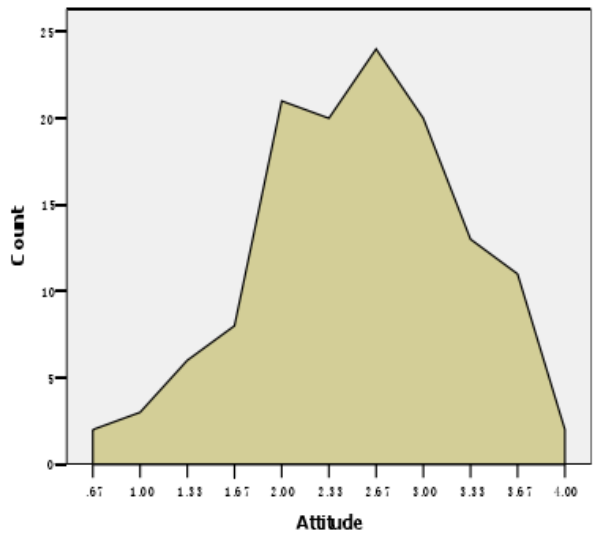

Under the Attitude dimension, the respondents displayed high level of willingness to learn English language and the western culture, which is a good sign to the ELT in China. At least English language practitioner in China may generally believe that students have a strong motivation and interest in Intercultural Communication.

B. The Awareness Dimension

Figure 2 Distribution of Awareness Dimension

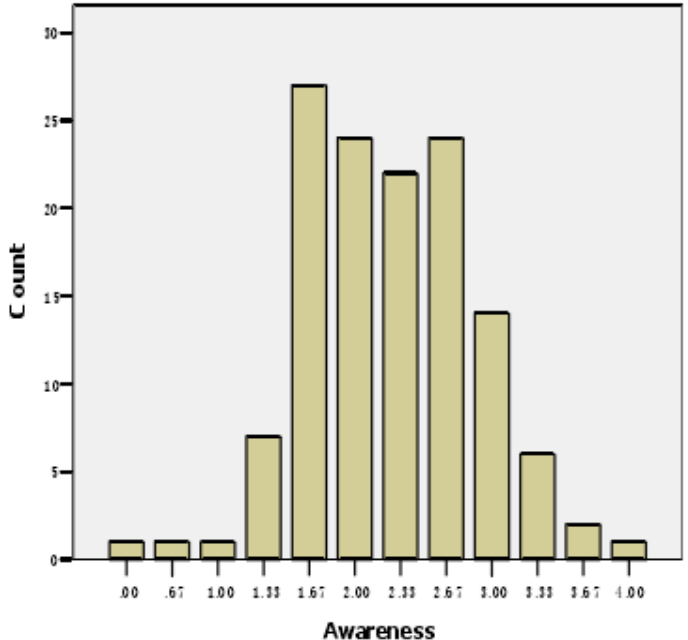

After years and years of exposure to English language, the sample participants demonstrated a certain level of either conscious or unconscious awareness towards language and culture, which is also a positive outcome of the Chinese ELT system. Here in the below is the distribution of Awareness dimension scores.

\section{A. The Knowledge Dimension}

Figure 3 Distribution of Knowledge Dimension

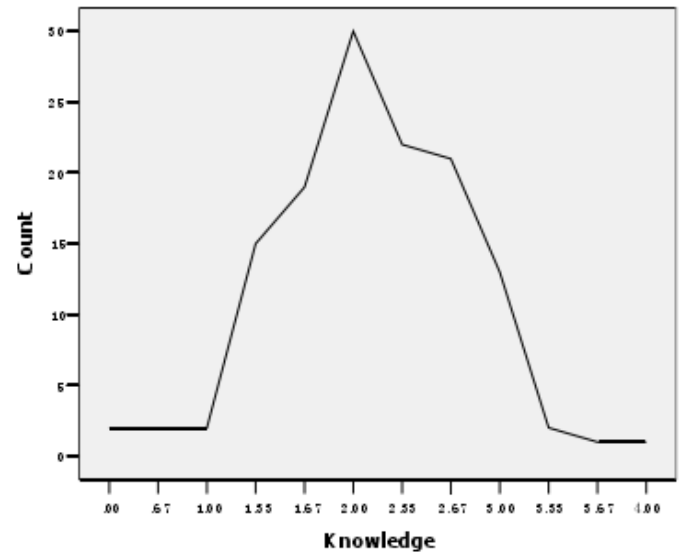

The knowledge dimension score ranked the third among all the four dimensions, which is also 
to our surprise. The tradition of Chinese ELT is to pass on knowledge no matter it is practical or not to learners as much as possible for it is a part our own cultural psychology that knowledge is everything. However, the respondents reported that they are lack of knowledge concerning cultural difference between western and oriental. The deeply-rooted reason may lie in the incompetent language instructors' own inadequacy in cultural knowledge and culture-related training.

\section{The Skills Dimension}

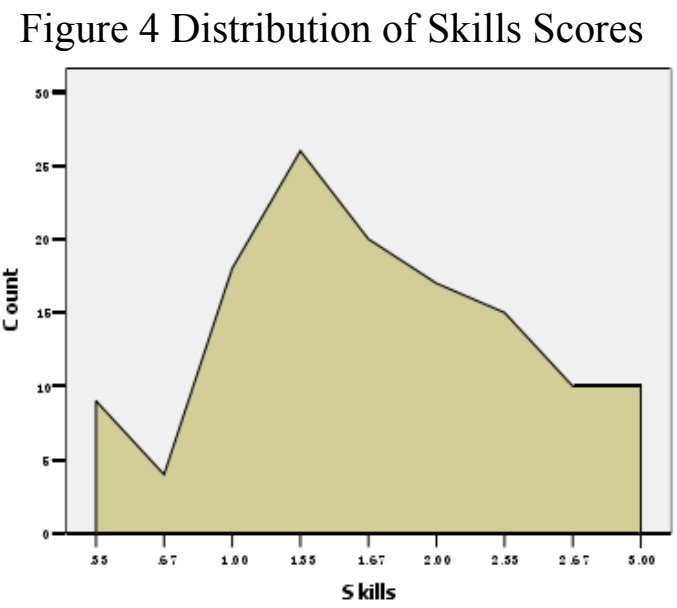

Skills category is worst ICC dimension that these candidates reported. Skills are not something formalized or structuralized which can be upgraded or enhanced by teachers' lectures or classes. Intercultural skills requires frequent exposure to actual situations of communications, which is a bit impossible to these participants as they have few opportunities to be involved in such circumstances and they have very limited time in putting the English into real practice. Thus the Skills dimension suffers the worst score among all the four categories.

\section{E. English Proficiency and Intercultural Communication Competence}

Table 2 Correlation Between CET 4 and Overall Competence

\begin{tabular}{|ll|r|r|}
\hline & & CET 4 Score & \multicolumn{1}{c|}{ Overall } \\
\hline CET 4 Score & Pearson Correlation & 1 & $.379(* *)$ \\
& Sig. (2-tailed) & & .000 \\
& $\mathrm{~N}$ & 124 & 123 \\
Overall & Pearson Correlation & $.379(* *)$ & 1 \\
& Sig. (2-tailed) & .000 & \\
& $\mathrm{~N}$ & 123 & 129 \\
\hline
\end{tabular}

** Correlation is significant at the 0.01 level (2-tailed).

Figure 5 Scatter Graph of CET 4 \& Overall ICC

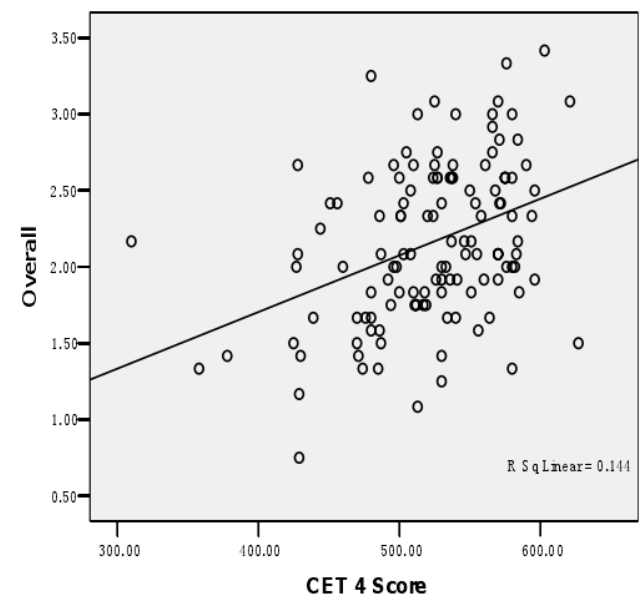


Table 3 Correlation between CEM \& Overall ICC

\begin{tabular}{|l|c|c|}
\hline & $\begin{array}{c}\text { Overal } \\
1\end{array}$ & $\begin{array}{c}\text { College } \\
\text { English } \\
\text { Module }\end{array}$ \\
\hline Overall & 1 & $.299(*$ \\
Pearson correlation & 129 & .001 \\
Sig.(2-tailed) & $.299(*$ & 128 \\
N & $*)$ & 1 \\
College English Module & .001 & 128 \\
Pearson Correlation & 129 \\
Sig. (2-tailed) & & \\
N & \\
N* Correlation is significant at the 0.01 level (2-tailed).
\end{tabular}

From the below table and graph, it is safe to draw the conclusion that the participants' CET 4 Scores are correlated with their ICC level, which proves that language proficiency enjoys correlation with ICC to some extent.

\section{Conclusion}

Based upon limited conditions, it is relatively safe to conclude that language proficiency is correlated to ICC level, which means if one's language proficiency is good, his or her ICC will be expectedly good. This is an interesting phenomenon that if we can improve the learners' English language proficiency, does that mean their ICC command is also correspondingly elevated? This would be an interesting area of further research. In this survey study the sample is relatively small. The limited number of student participants cannot represent the actual situation of today's Chinese Non-English majors' intercultural communication competence.

\section{References}

[1] Lily A. Arasaratnam,Marya L. Doerfel. Intercultural communication competence: Identifying key components from multicultural perspectives [J]. International Journal of Intercultural Relations. $2005(2)$

[2] Neil Harrison. Investigating the impact of personality and early life experiences on intercultural interaction in internationalised universities $\mathrm{N}[\mathrm{J}]$. International Journal of Intercultural Relations. $2011(2)$

[3] Verena Behrnd, Susanne Porzelt. Intercultural competence and training outcomes of students with experiences abroad[J]. International Journal of Intercultural Relations . 2011 (2)

[4] Murat Hismanoglu. An investigation of ELT students' intercultural communicative competence in relation to linguistic proficiency, overseas experience and formal instruction [J]. International Journal of Intercultural Relations . 2011 (6)

[5] Philip H. Anderson, Leigh Lawton, Richard J. Rexeisen, Ann C. Hubbard. Short-term study abroad and intercultural sensitivity: A pilot study[J]. International Journal of Intercultural Relations. $2005(4)$ 